\section{Life Events}

Anna C. Phillips

School of Sport, Exercise \& Rehabilitation

Sciences, University of Birmingham,

Birmingham, UK

\section{Synonyms}

Stress; Stressful life events

\section{Definition (and Description)}

Life events are specific occurrences experienced by an individual that are perceived as stressful, e.g., bereavement, divorce moving house. Life events are not always negative events but can be something positive which is perceived as stressful due to the amount of change it brings into the individual's life, e.g., getting married changing job.

Life event measures are often used to identify relationships between stress and health within behavioral medicine research. Life events are usually assessed by standardized interview or questionnaire. Such questionnaires ask the individual to indicate which events have happened to them over a specific time period such as one year or one month. Life events are usually limited to several key domains such as health, marriage, relationships, bereavement, work, housing, and finance. Some life event measures are specific to DOI 10.1007/978-1-4614-6439-6_468-3 certain populations or age groups such as the Life Events Scale for Students (Linden 1984). These measures often ask individuals to rate how stressful each event that occurred was on a rating scale. This method is based on the well-established Life Events and Difficulties Schedule (Brown and Harris 1989). Other questionnaires use pre-identified weightings of the severity of events to determine an overall life event burden score, such as the Undergraduate Stress Questionnaire (Crandall et al. 1992) in which more severe events such as bereavement are given higher weightings.

\section{Cross-References}

$\checkmark$ Perceived Stress

- Perceived Stress Scale PSS

$>$ Stress

\section{References and Further Readings}

Brown, G. W., \& Harris, T. O. (1989). Social origins of depression: A study of psychiatric disorder in women. London: Routledge.

Crandall, C. S., Preisler, J. J., \& Aussprung, J. (1992). Measuring life event stress in the lives of college students: The undergraduate stress questionnaire (USQ). Journal of Behavioral Medicine, 15, 627-662.

Linden, W. (1984). Development and initial validation of a life event scale for students. Canadian Counsellor, 18, 106-110. 